\title{
Effects of atmosphere-ocean interaction on the interannual variability of winter temperature in Taiwan and East Asia*
}

Received: 22 October 1999 / Accepted: 5 June 2000

\begin{abstract}
This study investigated the ocean-atmosphere interaction effect on the winter surface air temperature in Taiwan. Temperature fluctuations in Taiwan and marine East Asia correlated better with a SST dipole in the western North Pacific than the SST in the central/ eastern equatorial Pacific. During the warm (cold) winters, a positive (negative) SST anomaly appears in marine East Asia and a negative (positive) SST anomaly appears in the Philippine Sea. The corresponding lowlevel atmospheric circulation is a cyclonic (anticyclonic) anomaly over the East Asian continent and an anticyclonic (cyclonic) circulation in the Philippine Sea during the warm (cold) winters. Based on the results of both numerical and empirical studies, it is proposed that a vigorous ocean-atmosphere interaction occurring in the western North Pacific modulates the strength of the East Asian winter monsoon and the winter temperature in marine East Asia. The mechanism is described as follows. The near-surface circulation anomalies, which are forced by the local SST anomaly, strengthen (weaken) the northeasterly trade winds in the Philippine Sea and weaken (strengthen) the northeasterly winter monsoon in East Asia during warm (cold) winters. The anomalous circulation causes the SST to fluctuate by modulating the heat flux at the ocean surface. The SST anomaly in turn enhances the anomalous circulation. Such an ocean-atmosphere interaction results in the rapid development of the anomalous circulation in the western North Pacific and the anomalous winter temperature in marine East Asia. This interaction is phase-
\end{abstract}

* This paper is a contribution to the AMIP-CMIP Diagnostic
Subproject on General Circulation Model Simulation of the East
Asian Climate, coordinated by W.-C. Wang

H.-H. Hsu $(\bowtie) \cdot$ W.-S. Kau

Department of Atmospheric Sciences,

National Taiwan University, Taipei, Taiwan

E-mail: hsu@atmos1.as.ntu.edu.tw

Y.-L. Chen

Central Weather Bureau, Taipei, Taiwan locked with the seasonal cycle and occurs most efficiently in the boreal winters.

\section{Introduction}

The El Niño/Southern Oscillation (hereafter referred to as ENSO) is one of the major phenomena affecting the interannual climate variability in many regions around the world (e.g., Pan and Oort 1983; Ropelewski and Halpert 1987, 1989, 1996; Lau and Sheu 1988; Kiladas and Diaz 1989; Halpert and Ropelewski 1992). The major climatic impact of ENSO is mostly restricted to the tropics and the Asian summer monsoon region. The former is largely attributed to the variation in east-west oriented circulation, i.e., Walker circulation, while the latter has been suggested to result from the change in land-sea thermal contrast ( $\mathrm{Li}$ and Yanai 1996; Ju and Slingo 1995).

In contrast to the extensive impact on the tropics, the overall ENSO impact on the subtropical and extratropical climate is mostly regional and is often difficult to quantify. Among the affected subtropical and extratropical regions, the ENSO-related climatic variation is most obvious in the North American continent through the propagation of Rossby wave-like disturbances (Horel and Wallace 1981; Hoskins and Karoly 1981). In the western North Pacific and East Asia, one of the most obvious impacts is the warm and cold winters during the mature phase of El Niño and La Niña, respectively (Ropelewski and Halpert 1987; Halpert and Ropelewski 1992). The milder winter in East Asia is consistent with the composite wind anomalies shown in Rasmusson and Carpenter (1982) and the correlation pattern shown in Hsu (1994). Both studies suggested the existence of an anticyclonic anomaly in the western North Pacific during El Niño and, therefore, the weaker surface northeasterly winds in East Asia. Zhang et al. (1996, 1997) also found that the East Asian winter monsoon tends to be weaker during the mature phase of El Niño. 
Kitoh (1988) found that the sea surface temperature (hereafter referred to as SST) in the central equatorial Pacific leads the December surface air temperature (hereafter referred to as SAT) in Japan by 2-3 months. The warm SAT in Japan is associated with a weaker surface anticyclone in Siberia and China. While the result seems to be consistent with those described in the preceding paragraph, Kitoh (1988) found that the January and February SAT in Japan is not significantly correlated with the SST in the central equatorial Pacific. Instead, the SAT in December, January, and February are all positively correlated with the SST in the western North Pacific near Japan and negatively correlated with the SST in the region farther southeastward. The results imply the potential impacts of the SST in the western North Pacific on the East Asian winter climate, although it was not emphasized in Kitoh (1988).

Wang et al. (2000) recently noted the existence of a Pacific-East Asia teleconnection pattern with alternative cyclonic and anticyclonic vorticity anomalies emanating from the equatorial central Pacific northwestward to East Asia during El Niño and La Niña. During El Niño (La Niña), an anticyclonic (cyclonic) anomaly appears at the western end of the pattern and may have a significant impact on the East Asian climate. These results are consistent with previous studies discussed. Wang et al. (2000) further suggested that a positive thermodynamic feedback between the anticyclonic (cyclonic) anomaly and the ocean mixed layer in the western North Pacific is responsible for the existence of this teleconnection. They also proposed that the SST fluctuations in the central/eastern equatorial Pacific play an essential role in the precondition of an environment favorable for ocean-atmosphere interaction in the western North Pacific.

The previous studies mentioned suggested that the winter temperature in East Asia might be possibly be affected by the SST fluctuations in both the western North Pacific (e.g., the oceanic region from southeast of Japan to the equator and the dateline) and the central/ eastern equatorial Pacific (e.g., the Niño 3 and 4 regions). However, the issue of how these SST fluctuations affect the East Asian winter climate has not been extensively investigated. Wang et al. (2000) explored the mechanism responsible for the establishment of the Pacific-East Asia teleconnection, which in turn affects the East Asian climate, during ENSO. However, their results can not explain the weak relationship between the January and February SAT in Japan and the SST in the central/eastern equatorial Pacific as noted by Kitoh (1988). In order to understand the potential impacts of SST fluctuations on the East Asian climate, it would be more appropriate to explore the issue by examining the corresponding ocean-atmosphere system during extreme climatic events in East Asia.

In this study, we investigated this relationship from the viewpoint of the East Asian climate without making a priori assumption of significant ENSO impact. An approach similar to that of Kitoh (1988) was taken to investigate the oceanic and atmospheric states that are closely related to the winter climate in Taiwan. Although only the station data in Taiwan were used as an index in this study, the results shown in Sect. 2 indicate that the variations in winter temperature in Taiwan are not an isolated local feature. Instead, they are highly correlated with a large-scale temperature pattern, which reflects the temperature variation in marine East Asia. Calculations taking this large-scale pattern as an index yield similar results similar to those presented here. Numerical simulations using a general circulation model were also carried out to investigate the relative contribution of SST variations in different regions in affecting the winter temperature in the concerned region.

The data used in this study and the analysis procedure are described in Sect. 2. Oceanic and atmospheric states that are closely related to the warm and cold winters in Taiwan are presented in Sects. 3 and 4. Section 5 presents the numerical simulation results. The physical mechanisms and conclusions are presented in Sect. 6.

\section{Data and analysis procedure}

Data used in this study include monthly mean data from (1) the National Centers for Environmental Prediction/National Center for Atmospheric Research (NCEP/NCAR) reanalysis, (2) the NCEP reconstructed sea surface temperature, and (3) the temperatures from 20 stations in Taiwan for the winters from 1958/59 to 1996/97. The winter here is defined as December, January, and February. The reanalysis and reconstructed SST are in a $2.5^{\circ}$ by $2.5^{\circ}$ and $1^{\circ}$ by $1^{\circ}$ grid, respectively.

In order to emphasize the large-scale temperature variation, the averaged temperature for all 20 Taiwan stations was calculated to represent an island-wide temperature fluctuation. Seasonal means were then computed to remove the month-to-month fluctuations. Table 1 lists the mean temperatures of 39 winters from the coldest to the warmest year. Winters that had a temperature deviation greater than one standard deviation were chosen. The screening process identified the five coldest winters $(1967 / 68,1962 / 63,1985 / 86,1983 / 84$, and 1973/74) and five warmest winters $(1965 / 66,1972 / 73,1978 / 79,1968 / 69$, and 1959/ 60). Composites of the various variables for the chosen winters were then calculated to represent the atmospheric circulation and sea surface temperature characteristics during the warm and cold winters. Similar calculations using a 0.5 standard deviation criterion were also performed and yielded similar results. This procedure ensures that the number of cases does not affect the results presented here.

One may suspect whether the temperature variation in Taiwan is representative of a large-scale fluctuation. The correlation coefficient map between the winter SAT in Taiwan and $1000 \mathrm{hPa}$ temperature shown in Fig. 1 indicates that the former is highly correlated with the latter in a large area covering marine East Asia, namely the northern South China Sea, Taiwan, and the Pacific south of Japan. The southeastern edge of this positively correlated region is bounded by a large correlation gradient extending from the Philippines northeastward to about $\left(25^{\circ} \mathrm{N}, 160^{\circ} \mathrm{E}\right)$. A positively correlated region is also found in the central/eastern equatorial Pacific, but this correlation is much lower than the correlation in marine East Asia. Between the two positively correlated regions, a negatively correlated region exists in Micronesia and the eastern North Pacific. This pattern clearly demonstrates that the winter SAT fluctuation in Taiwan is linked to a large-scale temperature fluctuation and can be representative of the winter temperature fluctuation in marine East Asia. 


\section{SST and circulation}

\subsection{SST}

Correlation coefficients between the SAT in Taiwan and the SST in the North Pacific are shown in Fig. 2a. A positive-negative-positive pattern, which bears a similar spatial distribution to the pattern shown in Fig. 1, can be clearly seen in the Pacific. The similarity between these two suggests the highly coupled nature of the atmosphere and ocean in this area. Composites of normalized SST for the five warmest and coldest winters are shown in Fig. $2 b$ and c, respectively. The normalized SST anomalies are presented here to more clearly show the SST fluctuation in the western North Pacific because of its relatively smaller standard deviation. During the warmest winters, above normal SST is found in two

Table 1 Winter SAT anomaly in Taiwan from 1958/59 to 1998/99. Years in italic and bold type are anomalies greater than one standard deviation and are chosen for composites. Years in italic type are anomalies greater than 0.5 standard deviation. Winters of El Niño and La Niña are also marked. Data of 97/98 and 98/99 winters are listed for reference only and are not included in calculation

\begin{tabular}{|c|c|c|c|c|c|c|c|}
\hline DJF & SAT & El Niño & La Niña & DJF & SAT & El Niño & La Niña \\
\hline $67 / 68$ & -2.86 & & & $84 / 85$ & 0.04 & & $\mathrm{v}$ \\
\hline $62 / 63$ & -2.52 & & & $64 / 65$ & 0.15 & & $\mathrm{v}$ \\
\hline $85 / 86$ & -1.47 & & & $88 / 89$ & 0.15 & & $\mathrm{~V}$ \\
\hline $83 / 84$ & -1.45 & & & $77 / 78$ & 0.26 & $\mathrm{v}$ & \\
\hline $73 / 74$ & -1.38 & & $\mathrm{v}$ & $86 / 87$ & 0.33 & $\mathrm{~V}$ & \\
\hline $60 / 61$ & -0.72 & & & $58 / 59$ & 0.51 & & \\
\hline $61 / 62$ & -0.62 & & & $94 / 95$ & 0.53 & $\mathrm{v}$ & \\
\hline $76 / 77$ & -0.61 & $\mathrm{~V}$ & & $93 / 94$ & 0.73 & & \\
\hline $70 / 71$ & -0.60 & & $\mathrm{v}$ & $92 / 93$ & 0.75 & & \\
\hline $69 / 70$ & -0.59 & $\mathrm{~V}$ & & $74 / 75$ & 0.77 & & $\mathrm{~V}$ \\
\hline $75 / 76$ & -0.58 & & $\mathrm{v}$ & $90 / 91$ & 0.77 & & \\
\hline $81 / 82$ & -0.46 & & & $89 / 90$ & 0.86 & & \\
\hline $95 / 96$ & -0.41 & & $\mathrm{v}$ & $87 / 88$ & 0.87 & $\mathrm{v}$ & \\
\hline $82 / 83$ & -0.33 & $\mathrm{~V}$ & & $59 / 60$ & 0.97 & & \\
\hline $66 / 67$ & -0.30 & & & $68 / 69$ & 1.00 & $\mathrm{v}$ & \\
\hline $80 / 81$ & -0.23 & & & $78 / 79$ & 1.17 & & \\
\hline $91 / 92$ & -0.15 & $\mathrm{~V}$ & & $72 / 73$ & 1.31 & $\mathrm{v}$ & \\
\hline $63 / 64$ & -0.13 & $\mathrm{~V}$ & & $97 / 98$ & 1.34 & $\mathrm{v}$ & \\
\hline $96 / 97$ & -0.12 & & & 98/99 & 1.55 & & \\
\hline $71 / 72$ & -0.09 & & $\mathrm{v}$ & $65 / 66$ & 1.57 & $\mathrm{v}$ & \\
\hline $79 / 80$ & -0.02 & $\mathrm{v}$ & & & & & \\
\hline
\end{tabular}

regions, namely, the marine East Asia and the central/ eastern equatorial Pacific. At the same time, a negative anomaly region is located in the Philippine Sea and Micronesia, which has largest amplitude in the region from $0^{\circ} \mathrm{N}-15^{\circ} \mathrm{N}$ and $130^{\circ} \mathrm{E}-160^{\circ} \mathrm{E}$. The normalized SST anomaly for the five coldest winters exhibits a similar distribution but with reversed signs. The anti-symmetry of the SST patterns, during the warmest and coldest winters, yields a strong correlation pattern as shown in Fig. 2a. This SST teleconnection pattern resembles those shown in Kitoh (1988) and Wang et al. (2000).

A student $t$-test at the 0.05 significance level was applied to the pattern described. The significant changes in SST associated with the warmest and coldest winters, as shown by the shading in Fig. 2b, c, are mostly found in the two centers at the western part of the teleconnection pattern. This result suggests that the winter SAT fluctuation is more closely correlated with the smaller but significant SST fluctuations in the western Pacific than with those larger but less significant SST fluctuations in the central/eastern equatorial Pacific.

\subsection{Local versus remote SST}

Figure 3a shows a scatter diagram between the SAT in Taiwan and the SST in Niño 3.4 region $\left(5^{\circ} \mathrm{N}-5^{\circ} \mathrm{S}\right.$, $120^{\circ} \mathrm{W}-170^{\circ} \mathrm{W}$ ) during the boreal winter. The correlation coefficient between these two time series is 0.41 , which is statistically significant based on the no correlation null hypothesis. However, this suggests only a weak statistical relationship in terms of the explained variance percentage. Table 1 lists the SAT in Taiwan from the coldest to the warmest winters. The SATs for the 1997/98 and 1998/99 winters are also included in Table 1 for reference but are not used in the calculation. The corresponding El Niño and La Niña events, which are defined as suggested by Trenberth (1997), are also marked. Table 1 indicates that while the three warmest winters occurred during El Niño, only one coldest winter occurred during La Niña. The coldest and warmest winters in Taiwan often did not occur in $\mathrm{La}$ Niña or El Niño years. The most recent example is the La Niña winter of 1998/99, which was the record warm winter in many places in East Asia and the second warmest year in Taiwan over the past forty years.
Fig. 1 Correlation coefficients between the winter SAT in Taiwan and the $1000 \mathrm{hPa}$ temperature. The contour interval is 0.1 and negative values are contoured using a by dashed line. Correlation coefficients less than 0.3 and greater than -0.3 are not contoured

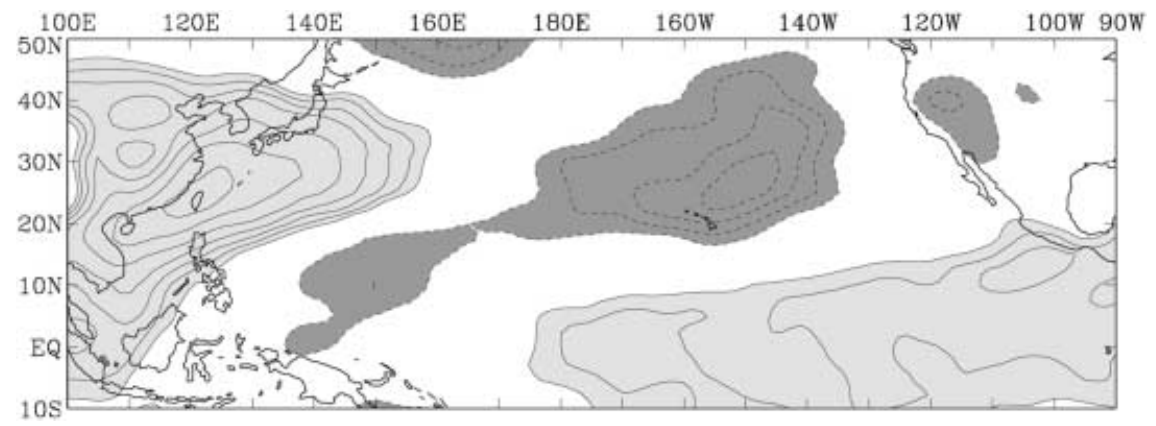


Fig. 2 a Correlation coefficients between the SAT in Taiwan and the SST in the Pacific, and the composites of normalized SST anomalies for the five $\mathbf{b}$ warmest and $\mathbf{c}$ coldest winters in Taiwan. The contour intervals are 0.1 in $\mathbf{a}$ and 0.3 in b and c. Negative values are contoured using a dashed line and the zero line is not plotted. Correlation coefficients between 0.3 and -0.3 are not contoured. Shading shown in $\mathbf{b}$ and $\mathbf{c}$ indicates the area where the SST anomalies are significant at 0.05 level. The rectangular box in a indicates the region chosen for constructing the WNPSST index

Fig. 3a, b Scattered diagram of SAT in Taiwan and a Niño 3.4 index and $\mathbf{b}$ WNPSST index

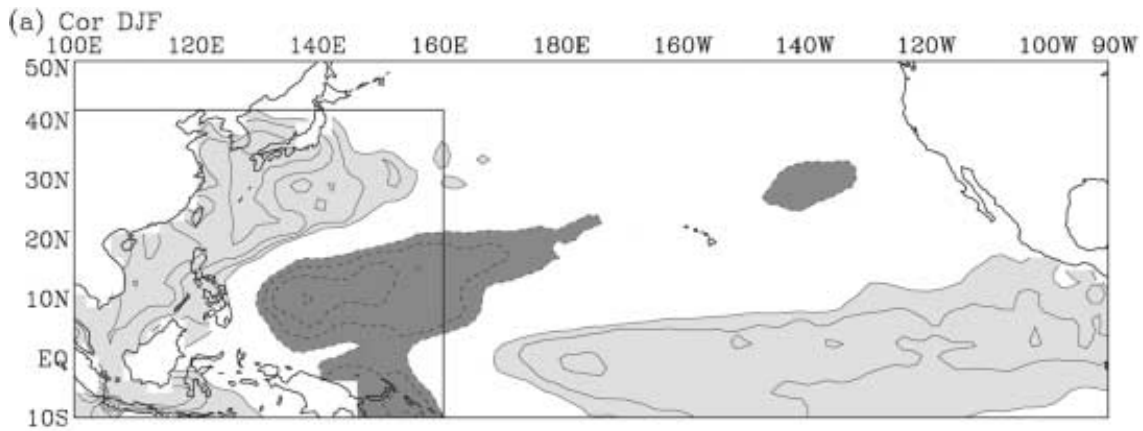

(b) WARM years $\rightarrow 65,72,78,68,59$

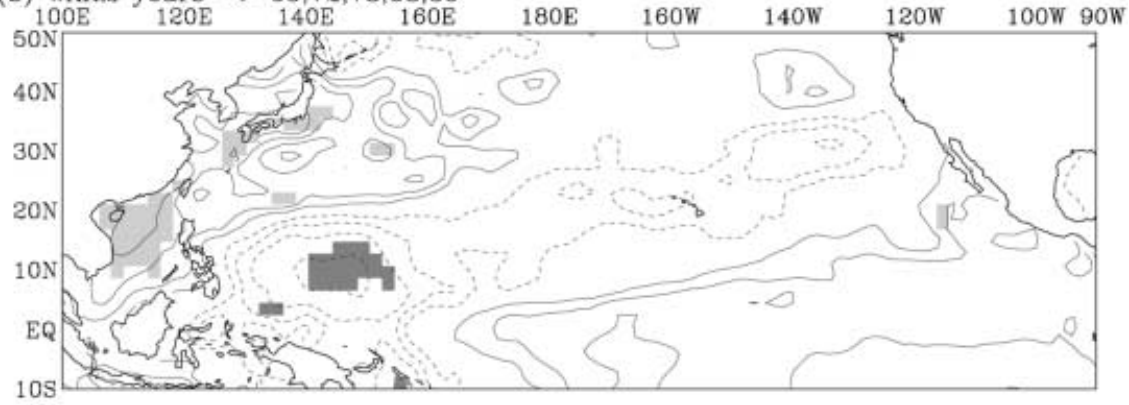

(c) COLD years $\rightarrow 67,62,83,85,73$
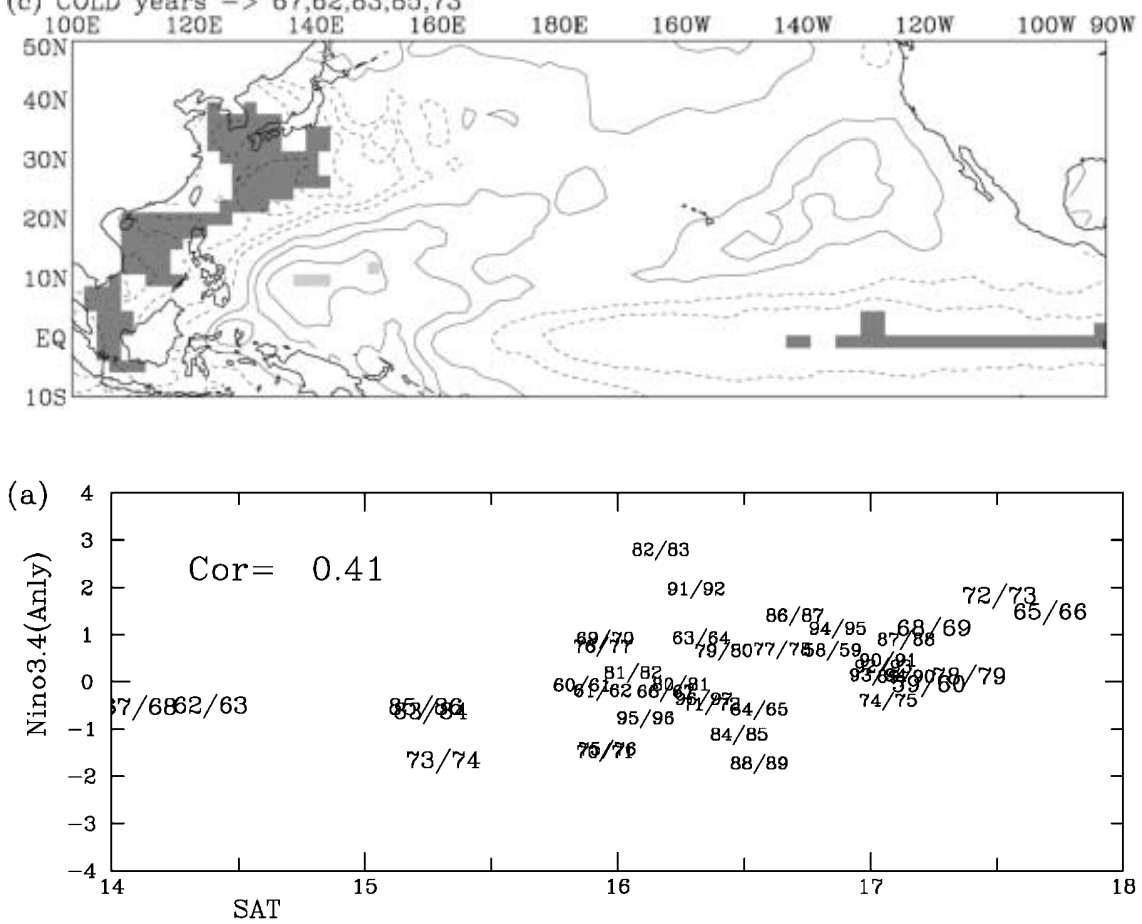

(b)

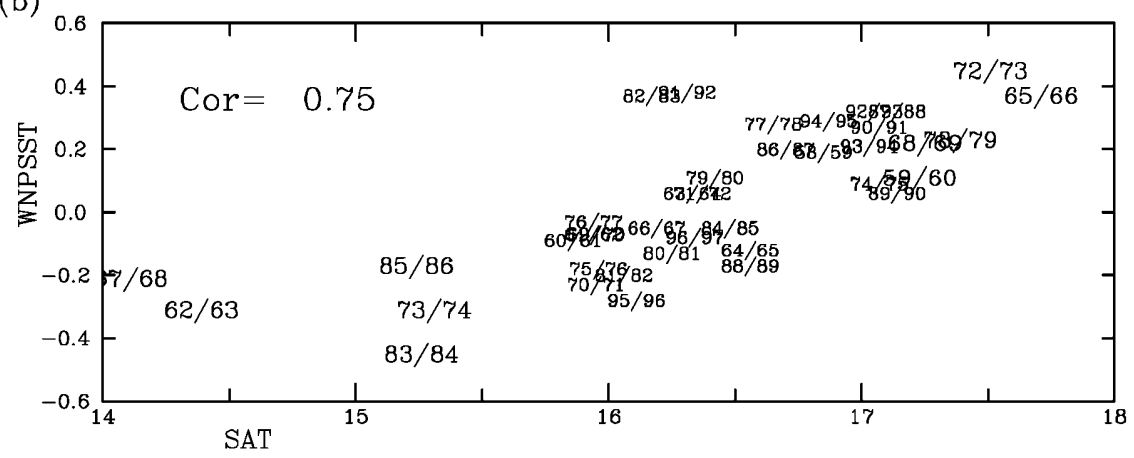


In contrast to the Niño 3.4 index, the SST dipole pattern in marine East Asia and the Philippine Sea/ Micronesia region is highly correlated with the SAT in Taiwan. A Western North Pacific SST index (WNPSST) is designed to represent the fluctuation of the SST dipole based on the correlation pattern shown in Fig. 2a. The WNPSST index is defined as the difference between the area mean of the SST anomalies in the positive correlation region (greater than 0.4 ) and the area mean in the negative correlation region (less than -0.4 ) in the rectangular region marked in Fig. 2a. A scatter diagram of the WNPSST index and the SAT of Taiwan is presented in Fig. 3b. The correlation coefficient between these two time series is as high as 0.75 , explaining more than half of the variance. It seems likely that the regional SST in the western North Pacific has a stronger impact on the winter SAT in Taiwan and marine East Asia than the remote SST in the central/eastern equatorial Pacific. This result is in good agreement with those shown in Kitoh (1988).

\subsection{Circulation}

The normalized mean sea level pressure (MSLP) anomaly pattern associated with the warmest winters (Fig. 4a) is characterized by a cyclonic anomaly in East Asia, an anticyclonic anomaly in the Philippine Sea and Micronesia, and another anticyclonic anomaly in the central North Pacific between $20^{\circ} \mathrm{N}$ and $50^{\circ} \mathrm{N}$. This anomaly pattern is associated with a southwestern wind anomaly in marine East Asia and a northeastern wind anomaly in the Philippine Sea and Micronesia at
$850 \mathrm{hPa}$. During the coldest years, a similar anomalous circulation with an opposite sign is observed (Fig. 4b). It is interesting to note that interannual fluctuations of winter temperature in marine East Asia are associated with the circulation anomalies not only over the Asian continent but also in the western North Pacific.

The warmest and coldest winters in Taiwan and marine East Asia are apparently associated with the weakening and strengthening of the northeastern monsoon (i.e., Asian winter monsoon) in East Asia, respectively. These results are consistent with the findings of previous studies (Kitoh 1988; Zhang et al. 1996; Wang et al. 2000). Our results suggest that the trades strengthen during the warm winters and weaken during the cold winters. The flow pattern described will also lead to an out-of-phase relationship between the temperature fluctuations in marine East Asia and the Philippine Sea/Micronesia region.

The MSLP and SST anomalies are phase shifted in such a manner that a negative (positive) SST anomaly is located at the southeastern (northwestern) flank of the positive MSLP anomaly in the Philippine Sea and Micronesia during the warm winters. This configuration indicates that a southwesterly anomaly prevails over the positive SST anomaly and a northeasterly anomaly prevails over the negative SST anomaly. A similar relationship, but with reversed polarity, is evident during the cold winters.

The normalized divergence anomaly at $850 \mathrm{hPa}$ for the warm winter cases is shown in Fig. 5. During the warm winters, a positive anomaly is found in the Philippine Sea and Micronesia while a negative anomaly is found in the South China Sea and the region near $30^{\circ} \mathrm{N}$
Fig. 4a, b Composites of $850 \mathrm{hPa}$ wind anomaly and normalized mean sea level pressure anomaly for the five a warmest and $\mathbf{b}$ coldest winters in Taiwan. The contour interval is 0.3 . Negative values are contoured using a dashed line and the zero line is not plotted
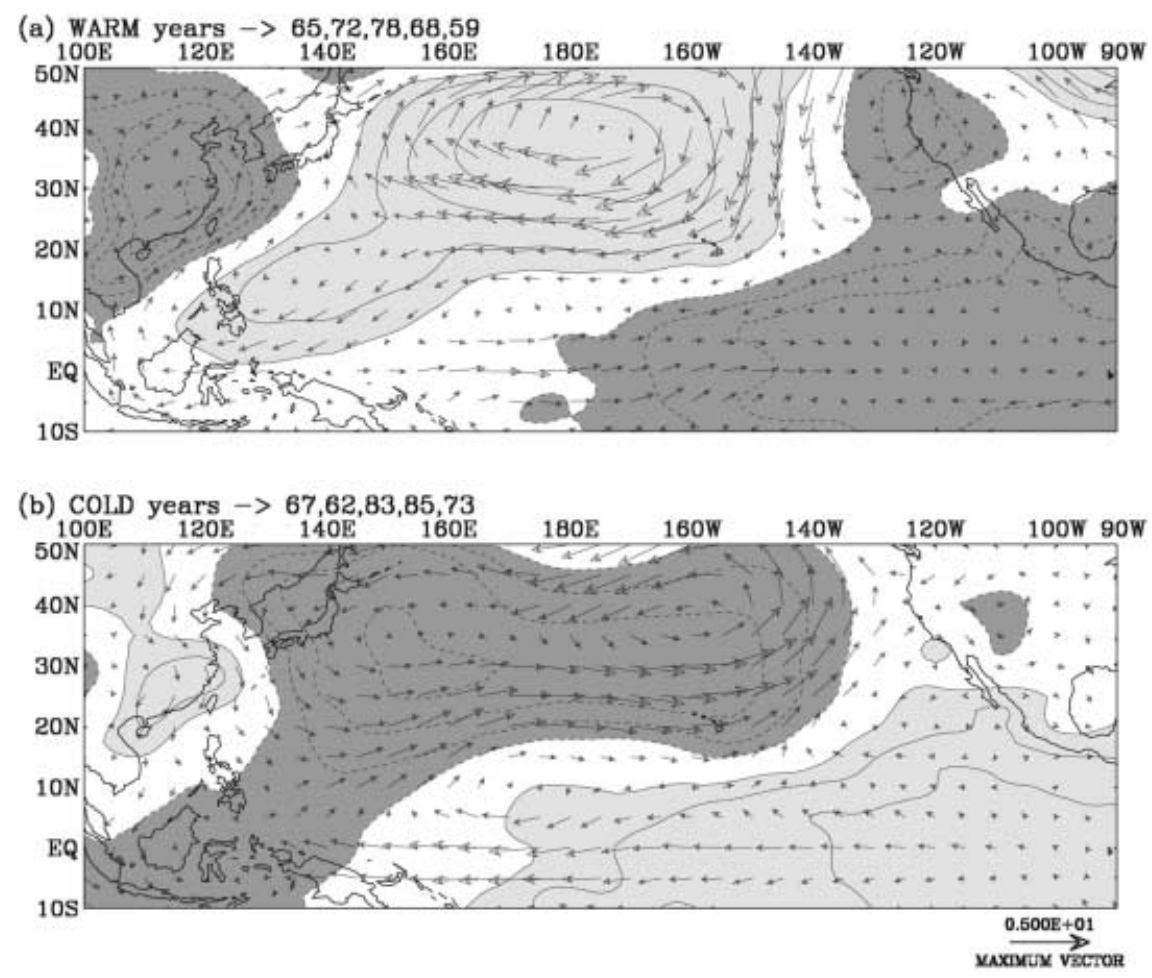
Fig. 5 Composites of normalized $850 \mathrm{hPa}$ divergence anomaly for the five warmest winters in Taiwan. Contour interval is 0.3 . Negative values are contoured using a dashed line and the zero line is not plotted

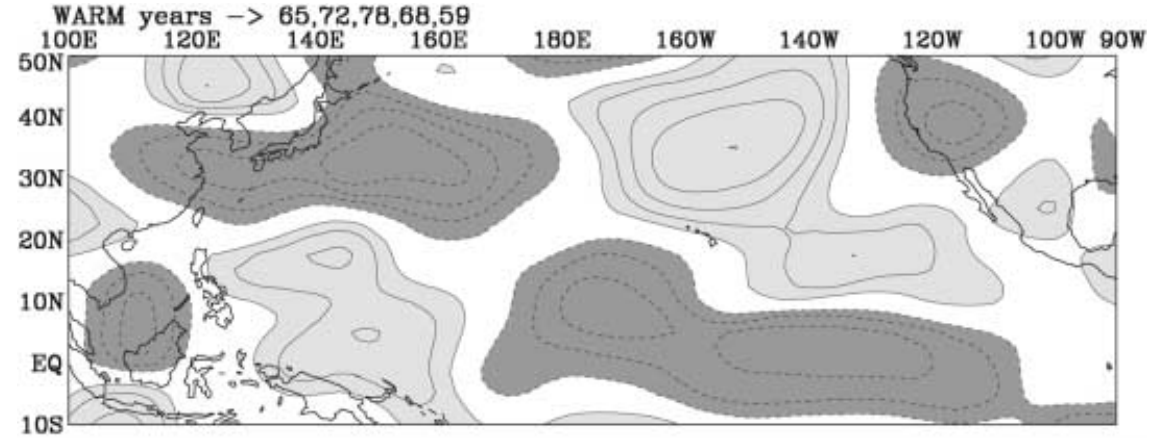

from $100^{\circ} \mathrm{E}$ to the dateline. These convergence (divergence) anomalies appear to be located over a positive (negative) SST anomaly. A comparison between the divergence anomaly fields at 850 and $200 \mathrm{hPa}$ indicates a general out-of-phase relationship between the two (not shown), suggesting the association of a convergence (divergence) anomaly with a deep heating (cooling) profile. One can easily see that, in the western North Pacific, the convergence/divergence anomaly spatial pattern also tends to be in quadrature with the MSLP anomaly, e.g., a divergence (convergence) anomaly located east or southeast of a positive (negative) pressure anomaly. The general relationship described also holds during the cold winters (not shown).

\section{Surface heat flux}

The results described reveal a coherent relationship between the SST and near-surface atmospheric circulation anomalies. It would be interesting to explore how the atmosphere and ocean interact through the exchange of surface heat fluxes. Because of the antisymmetrical nature of the warm and cold winters anomalies, the following discussion will focus on the warm winter anomalies. The latent heat flux anomaly during the warm winters is presented in Fig. 6a. Negative anomalies (less heat flux into the atmosphere) are found in a large area from the northern South China Sea northeastward to the central North Pacific. Maximum negative heat fluxes exist in the regions east of Taiwan and east of Japan neart $30^{\circ} \mathrm{N}$ with amplitudes of 52 and $40 \mathrm{Wm}^{-2}$, respectively. The former is associated with the southwesterly anomaly, i.e., a weaker northeasterly, while the latter is associated with the easterly anomaly, i.e., a weaker westerly. Weaker atmospheric circulation near the ocean surface seems to be responsible for the reduction in latent heat flux into the atmosphere.

South of the latent heat flux negative anomalies lies a positive anomaly region that is right beneath the northeasterly anomaly in the Philippine Sea and Micronesia. A stronger (weaker) northeastern flow in the trade wind region would encourage (suppress) evaporation cooling and lead to the decrease (increase) in SST. A similar pattern but with reversed signs is observed during the cold winters (not shown) while atmospheric circulation anomalies are in opposite phases.

A sensible heat flux field, shown in Fig. 6b, exhibits a pattern similar to that in the latent heat flux fleld. In the low latitudes, the typical sensible heat flux amplitudes are around $5-10 \mathrm{Wm}^{-2}$ and are much smaller than the latent heat flux with amplitude around $20-50 \mathrm{Wm}^{-2}$. This result suggests the dominance of evaporation cooling in the lower latitudes. However, the sensible heat flux amplitudes are compatible with the latent heat flux amplitudes in the region north of $30^{\circ} \mathrm{N}$ where the temperature differences between air and water become more prominent. The sensible heat flux fluctuates coherently with the variations in near-surface atmospheric circulation in a manner similar to the latent heat flux discussed.

An examination of the net radiation flux indicates a near cancellation between the net shortwave and longwave radiation and, thus, little contribution to the net surface heat flux (i.e., the sum of latent heat flux, sensible heat flux, and longwave and shortwave radiation). This can be realized by comparing the net heat flux, shown in Fig. 6c, with the latent and sensible heat fluxes. Generally speaking, the net heat flux anomaly is nearly the sum of the latent and sensible heat flux. During the warm winters, the largest negative heat flux anomalies appear near Taiwan and Japan with amplitudes exceeding 70 and $60 \mathrm{Wm}^{-2}$, respectively. On the whole, a net heat flux anomaly exceeding $20 \mathrm{Wm}^{-2}$ occurs in a large area of the western North Pacific. Differences between the warmest and coldest winters can amount to $150 \mathrm{Wm}^{-2}$ in some areas (not shown). This result indicates a large variation in the net heat flux from warm to cold winters and is likely to have a significant effect on the interannual variability of the winter climate in marine East Asia. In the region of $110^{\circ} \mathrm{E}-180^{\circ}$ and $0^{\circ}-$ $40^{\circ} \mathrm{N}$, the total negative (positive) heat flux anomaly apparently predominates the total positive (negative) heat flux anomaly during the warm (cold) winters. This result suggests that the subtropical region is the key area affecting the amount of heat supplied from the ocean into the atmosphere in the western North Pacific.

Positive and negative net heat flux anomalies can also be seen in the central/eastern equatorial Pacific during the warm and cold winters, respectively. These values are however much smaller than those observed in the western North Pacific despite the larger SST anomalies. 
Fig. 6a-c Composites of a latent heat flux, b sensible heat flux, and $\mathbf{c}$ net heat flux anomalies for the five warmest winters in Taiwan. Contour interval is $5 \mathrm{Wm}^{-2}$. Negative values are contoured using a dashed line and the zero line is not plotted
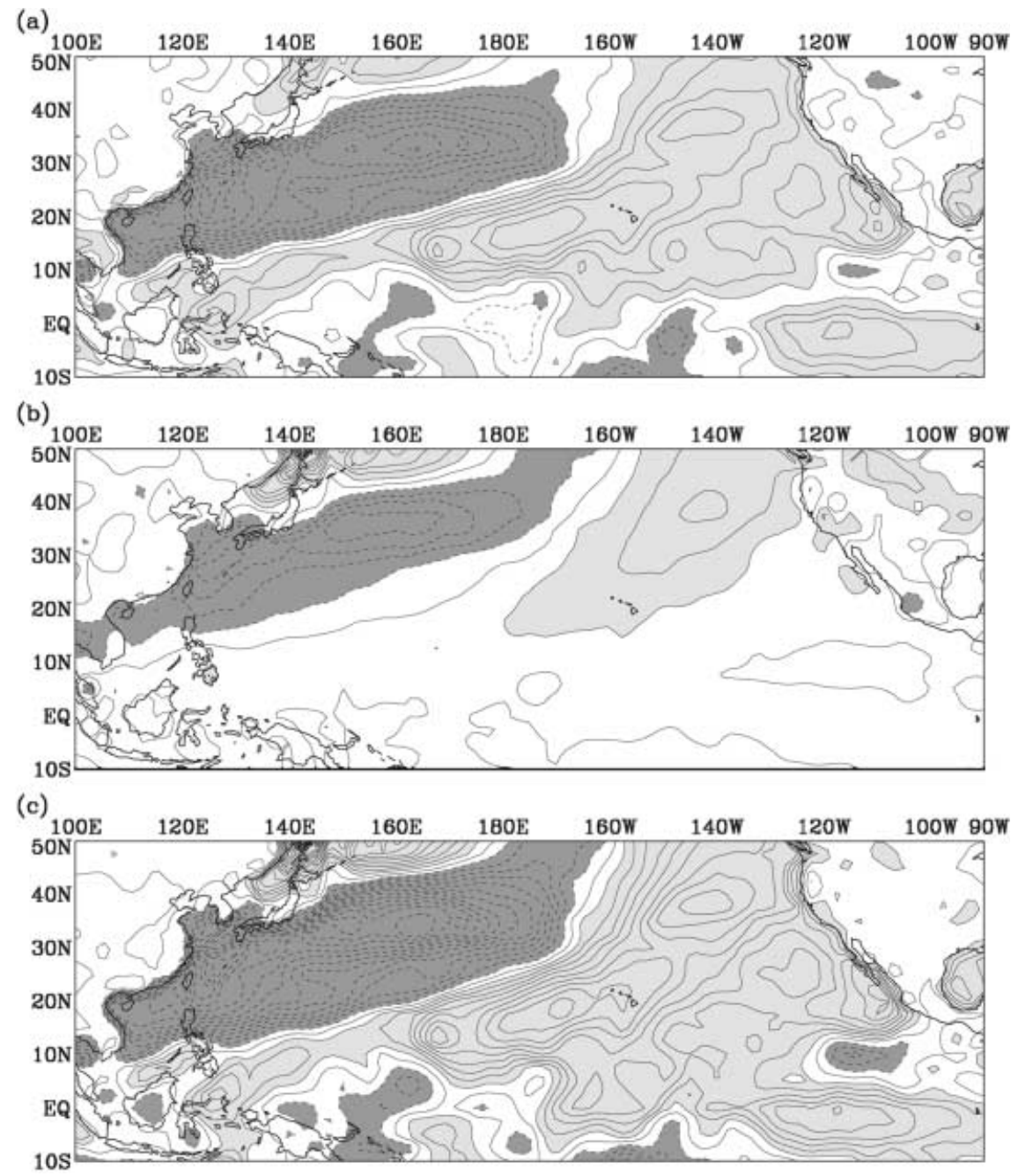

It is speculated that a small SST variation in the Western North Pacific may have a greater effect on the atmospheric circulation because of its greater efficiency in releasing heat into the atmosphere than its counterpart in the central/eastern equatorial Pacific.

\section{Numerical simulation}

As shown in Sect. 3, the spatial distributions of the SST and MSLP anomalies are in quadrature. It is tempting to see whether the anomalous SST can force the observed anomalous atmospheric circulation, which may in turn enhance the SST anomalies. A general circulation model (GCM) was used to simulate the atmospheric responses to various SST teleconnection pattern components to investigate the relative contribution of the SST anomalies in different regions. In this study, the National Taiwan University GCM (NTUGCM) was used for simulation. This model is a T42 12-level spectral model equipped with full physics, produces reasonable climatology in Atmospheric Model Intercomparison Project (AMIP) simulations forced by observed SST, and is capable of simulating the major features of the Asian monsoon (Kau 1998). A detailed description of the model can be found on the AMIP web page.

Ensemble simulations using the SST anomalies during the warm and cold winters as forcings were carried out in this study. Only those using warm winter forcings are presented here. Each simulation consists of four members, beginning at $00 \mathrm{Z}$, and $12 \mathrm{Z}$ on both 1 and 2 October and ending on 28 February. Results of the last 90 days were used to calculate the winter means. Averaged fields from December to February obtained from the control run, which was forced by climatological SST, were used as the model climatology. Four anomalous simulations, i.e., FULL, MEA/PHS, PHS, MEA, were produced by prescribing different combinations of SST anomalies in different regions in the model. The FULL simulation was forced by the entire SST anomalous pattern except for the component in the east North Pacific (Fig. 7a). The PHS and MEA simulations were forced by the negative SST anomaly in the Philippine Sea and Micronesia (Fig. 7d) and by the positive SST anomaly in the marine East Asian (Fig. 7c), respectively. The MEA/PHS simulation is forced by the 
combination of the SST anomalies used in the PHS and MEA simulations (Fig. 7b). Differences between the ensemble means of the anomalous and control runs were defined as anomalies and are compared to the observations shown in Sect. 3.

The $850 \mathrm{hPa}$ wind anomaly of the FULL simulation is shown in Fig. 8a. The following major features are well simulated: the cyclonic circulation in southeastern China, the anticyclonic circulation in the Philippine Sea, and the wave-like structure emanating from the central equatorial Pacific into the North Pacific and North America. The separation of the anticyclones in the Philippine Sea and the central North Pacific is also well simulated. The simulated southwestern anomaly (i.e., weaker northeasterly) in East Asia, which is accompanied by simulated warmer temperature (not shown), is consistent with the observed warmer temperature.

MEA/PHS simulation results are shown in Fig. 8b. The circulation anomalies in the Philippine Sea/Micronesia region and East Asia are still well simulated. However, the cyclonic/anticyclonic circulation pair in the central North Pacific and the downstream wave structure over North America are missing. Differences between the results of the FULL and WNP/PHS simulation results can be interpreted as the atmospheric responses to the SST anomaly in the central/eastern equatorial Pacific. This result, consistent with previous studies (e.g., Horel and Wallace, 1981; Hoskins and Karoly 1981), suggests that the missing features are mainly forced by the SST anomaly in the central/eastern equatorial Pacific. These results suggest that the anticy- clonic circulation in the Philippine Sea is forced mainly by the local SST anomaly. The SST anomaly in the central/eastern equatorial Pacific has little impact on the atmospheric circulation in the Philippine Sea and East Asia. These results also explain the separation of the anticyclonic anomalies in the Philippine Sea and the central North Pacific, because they are forced by the SST anomalies in different regions.

The importance of the local SST in the Philippine Sea and marine East Asia is demonstrated further in the MEA and PHS simulation as shown in Fig. 8c and d. Both MEA and PHS SST anomalies force an anticyclonic anomaly in the western Philippine Sea. The observed phase-shifted relationship between the SST anomalies and the near-surface atmospheric circulation in the western North Pacific is well simulated in both simulations. The atmospheric responses in both simulations are however weaker than those in the FULL simulation. Apparently, it would take both PHS and MEA SST anomalies to force a realistic anticyclonic anomaly in the Philippine Sea.

\section{Physical interpretation and conclusion}

Results presented in the preceding sections suggest that the ocean-atmosphere interaction in the western North Pacific may affect the winter SAT in East Asia. The physical mechanism for a warm event is proposed as follows, which also holds for a cold event but in an opposite sense.

\section{(a) SST FULL}

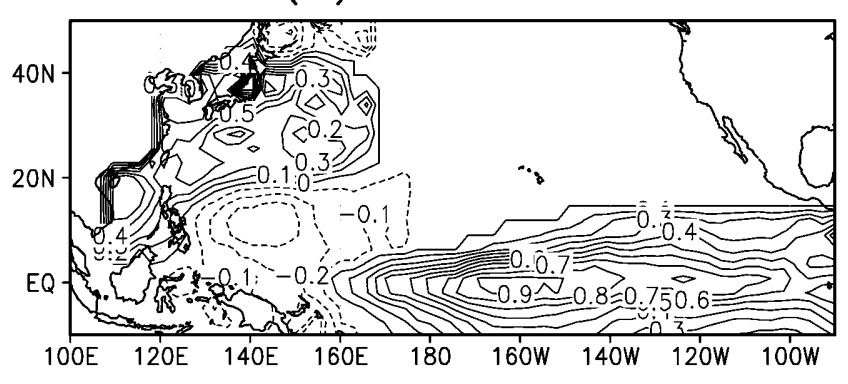

(b) SST MEA/PHS

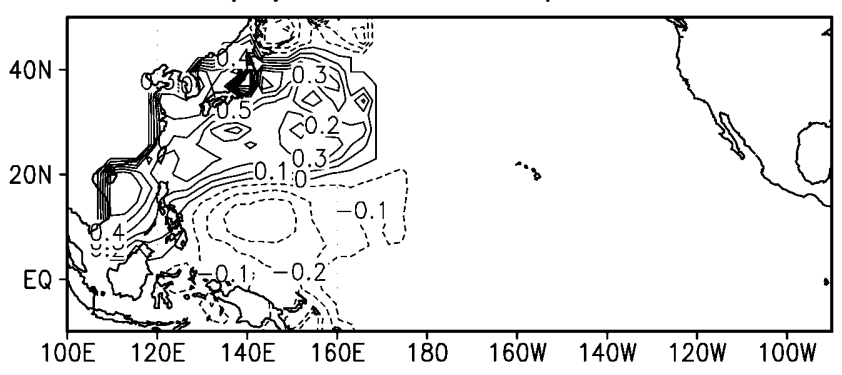

(c) SST MEA

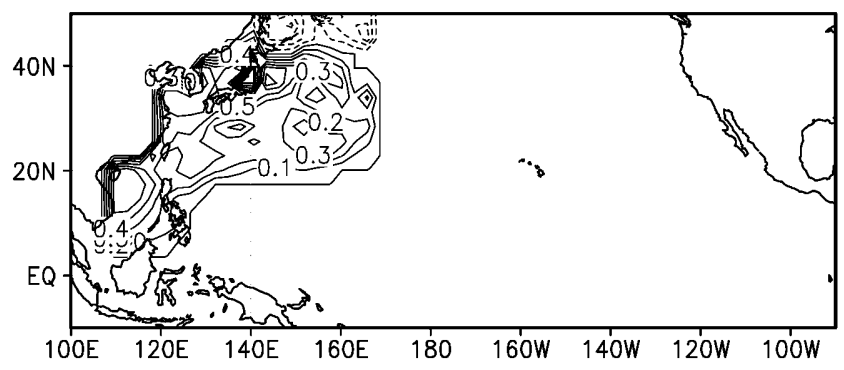

(d) SST PHS

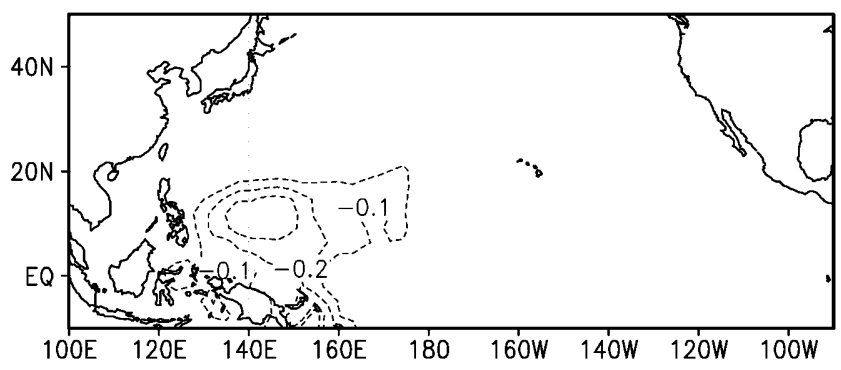

Fig. 7a-d The SST anomalies used in the following numerical simulations: a FULL, b MEA/PHS, $\mathbf{c}$ MEA, $\mathbf{d}$ PHS. Contour interval is $0.1{ }^{\circ} \mathrm{C}$. Negative values are contoured using a dashed line and the zero line is not plotted 


\section{(a) FULL}

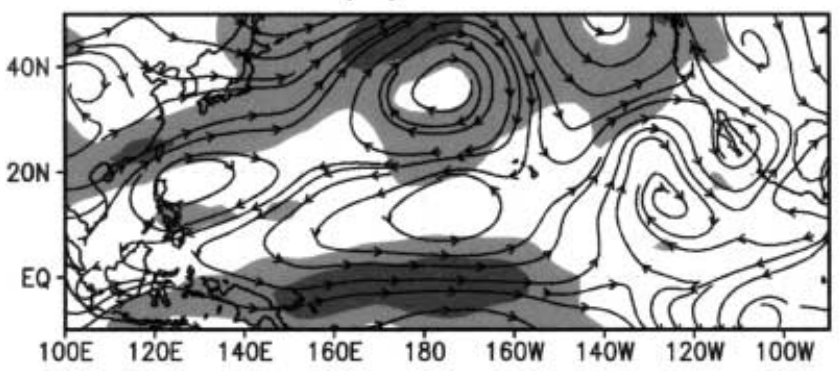

(b) MEA/PHS

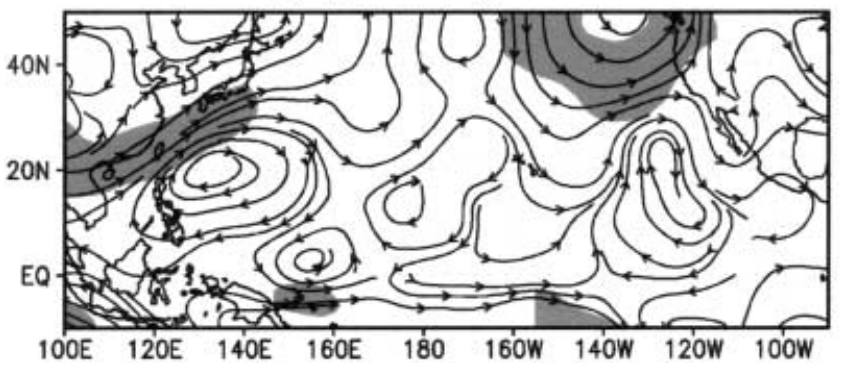

(c) MEA

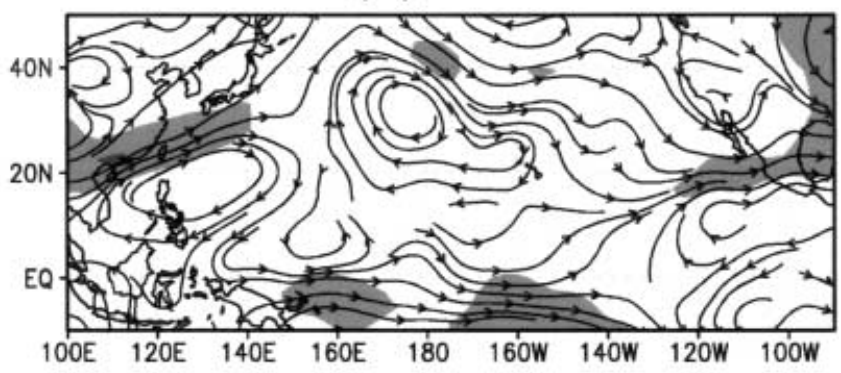

(d) PHS

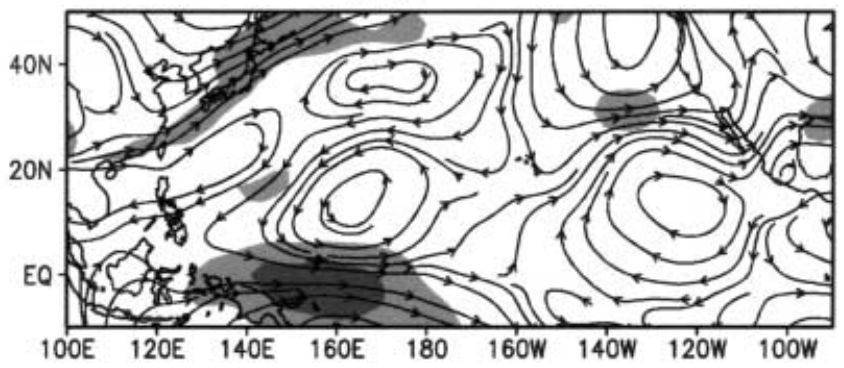

Fig. 8a-d Simulated $850 \mathrm{hPa}$ wind anomalies in the following numerical simulations: a FULL, b MEA/PHS, c MEA, d PHS. Light and dark shadings indicate where the anomalous wind speeds are larger than 1 and $2 \mathrm{~ms}^{-1}$, respectively

Our calculation, which is not shown here, revealed that in the warm winter cases a fully developed negative SST anomaly appeared in the Philippine Sea and Micronesia early in October and November, while the positive SST anomaly in marine East Asia was either weak or not apparent. This negative SST anomaly induces an anticyclonic anomaly, which has a configuration resulting in the northeasterly anomaly in the Philippine Sea/Micronesia region and the southwesterly anomaly in marine East Asia. Given the fact that northeasterly circulation prevails climatologically in both areas during boreal winters, the SST-wind relationship can be understood as follows. The southwesterly anomaly in marine East Asia reflects the weaker northeasterly circulation while the northeasterly anomaly in the Philippine Sea/Micronesia region indicates stronger trade winds. The former will extract less latent and sensible heat fluxes from the ocean and encourage less vertical mixing in the ocean mixing layer, while the latter will work in the opposite sense. These effects, if stronger than oceanic processes, can lead to the positive SST anomaly in marine East Asia and further enhance the negative SST anomaly in the Philippine Sea and Micronesia.

Figure 9 shows a composite time series of the WNPSST index and the WNP net heat flux (WNPNHF) index for both warm and cold winters. The WNPNHF index is defined in a manner similar to the WNPSST index but the chosen region is $105^{\circ} \mathrm{E}-180$ and $0-40^{\circ} \mathrm{N}$. Correlation coefficients are calculated between the SAT in Taiwan and the net heat flux in the Pacific. The area mean net heat flux in the region where correlation coefficients are less than -0.2 and in the region where correlation coefficients are larger than 0.2 are then computed. The difference between the two is defined as the WNPNHF index. Signs of this the index are chosen so that a positive (negative) sign represents more (less) heat flux into the atmosphere in the Philippine Sea/ Micronesia region and less (more) heat flux into the atmosphere in East Asia during the warm (cold) winters.

It is clearly demonstrated in Fig. 9 that the SST tends to lag behind the net heat flux by about 1-2 months. This result suggests that the low-level atmospheric circulation may force the SST variation through heat exchanges between the ocean and atmosphere. The climatological depth of mixed layer depth in the considered area is about $70 \mathrm{~m}$ according to Levitus (1982). Such a mixed layer can be cooled or warmed by about $0.5 \mathrm{~K}$ in two months by a net heat flux of $30 \mathrm{Wm}^{-2}$ without considering the oceanic dynamic effect. This rough estimate is consistent with the amplitudes of net heat flux shown in both Figs. 6 and 9 and supports the conjecture proposed above. The temporal phase shift between the SST and net heat flux also suggests that the winter temperature fluctuation in marine East Asia is mainly affected by the fluctuations in the northeasterly circulation and is not heated or cooled by the local SST.

Numerical simulations presented in this study have demonstrated the capability of the SST anomalies to force and maintain the observed near-surface atmospheric circulation. This can be understood as follows. The out-of-phase relationship between the low-level 
Fig. 9a, b Composite time series of the WNPSST and WNPNHF indices for the five a warmest and $\mathbf{b}$ coldest winters in Taiwan, which corresponds to JAN of year +1 . Values shown are three-month running means (a) Warm Winters(65/66 72/73 78/79 68/69 59/60)
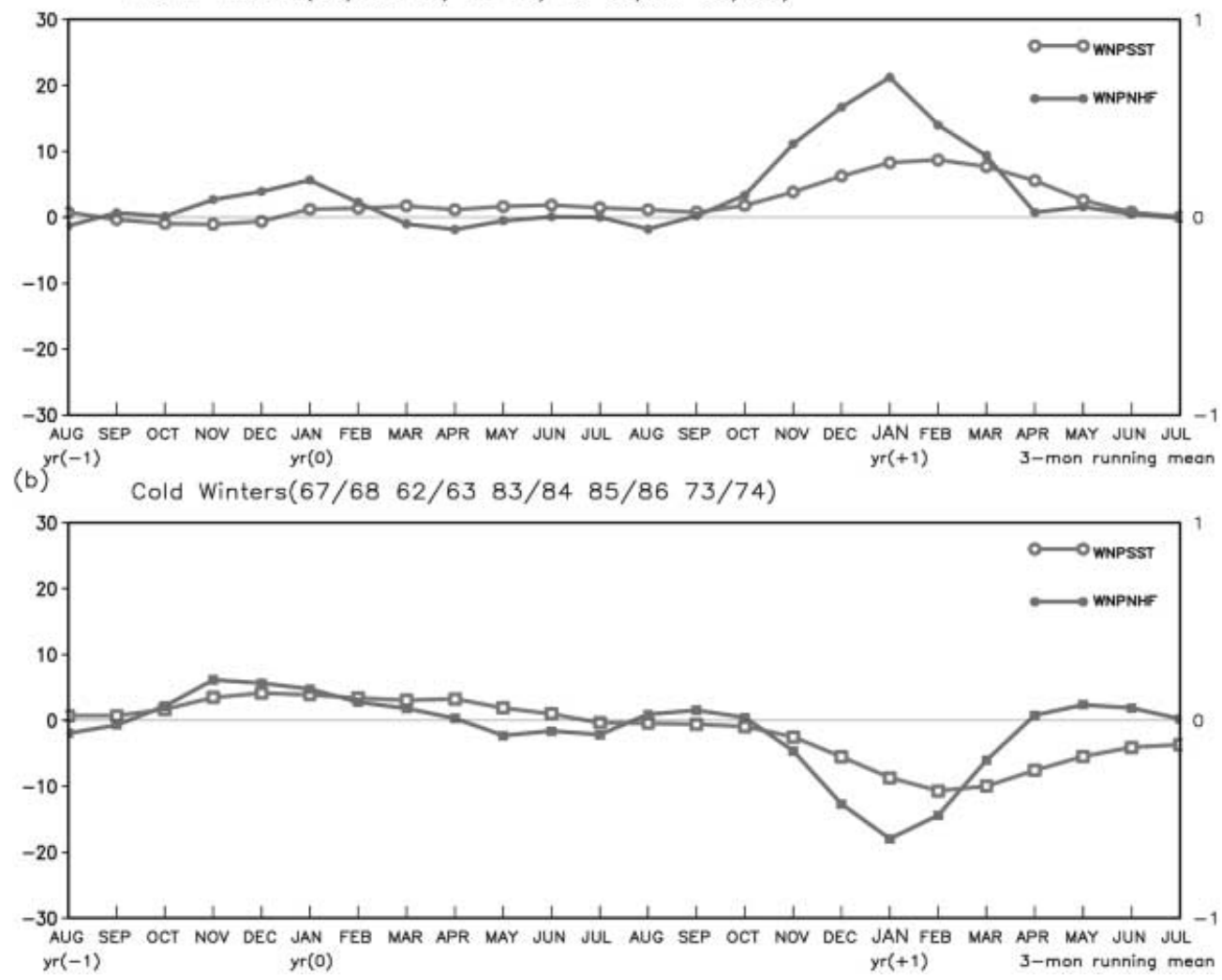

divergence and SST shown in Sect. 3 suggests that the ocean may act as a forcing to induce anomalous divergence near the surface. Anomalous cooling over the negative SST anomaly in the low latitudes can then force a low-level anticyclonic circulation northwest of its location (e.g., Hoskins and Karoly 1981; Gill 1980), which is consistent with the phase shift relationship between the divergence and circulation shown in Figs. 4 and 5 . The forced atmospheric circulation would further enhance or weaken the net heat flux at the surface and change the SST. The positive feedback between the ocean mixed layer and the near-surface atmosphere leads to a vigorous ocean-atmosphere interaction in the western North Pacific and also results in the rapid development of SST and atmospheric circulation anomalies. The proposed process, which is consistent with Wang et al. (2000), is likely to be one of the major mechanisms to affect the winter temperature in Taiwan and marine East Asia.

The ocean-atmosphere interaction described would be most effective during the boreal winter. In other words, it is phase-locked with the seasonal cycle. Because of the co-existence of the winter monsoon and the Kuroshio, the western North Pacific is climatologically one of the major sources of latent and sensible heat flux for the atmosphere. The amount of heat flux released into the atmosphere reaches its peak during the boreal winter, because of the strong wind, and large airsea temperature and humidity differences associated with the strong northeasterly and quickly developing synoptic disturbances. A slight but persistent change in near-surface atmospheric circulation or SST distribution can efficiently trigger a vigorous ocean-atmosphere interaction in the western North Pacific. It would be difficult for such an interaction to occur in the warm seasons because of the weaker winds and smaller air-sea temperature and humidity differences.

The weak correlation between the SAT in Taiwan and Niño 3.4 index suggests that the ENSO has only an indirect effect on the winter SAT in Taiwan and marine East Asia. It follows that a strong El Niño or La Niña event does not necessarily lead to the strong SST dipole in the western North Pacific and the major warm or cold winters in Taiwan and marine East Asia. Figure 10 presents a composite of normalized SST anomalies for the thirteen El Niño winters marked in Table 1. Although it is similar to the pattern shown in Figs. 2b and $4 \mathrm{a}$, marked differences are still evident, e.g., the amplitude distribution of normalized SST anomalies. For the El Niño cases, the normalized SST anomalies in the central/eastern equatorial Pacific are much larger than their counterparts in the western North Pacific. In contrast, during the warm winters in Taiwan, the normalized SST anomalies in the western North Pacific are greater than the normalized SST anomalies in the central/eastern equatorial Pacific.

Different SST amplitude distributions are likely to result in different atmospheric responses. The $850 \mathrm{hPa}$ wind anomaly presented in Fig. 10 indicates that stronger signals in El Niño cases are mostly located in 
Fig. 10 Composites of $850 \mathrm{hPa}$ wind and normalized SST anomalies for the 13 El Niño episodes marked in Table 1. The contour interval is 0.3 . Negative values are contoured using a dashed line and the zero line is not plotted

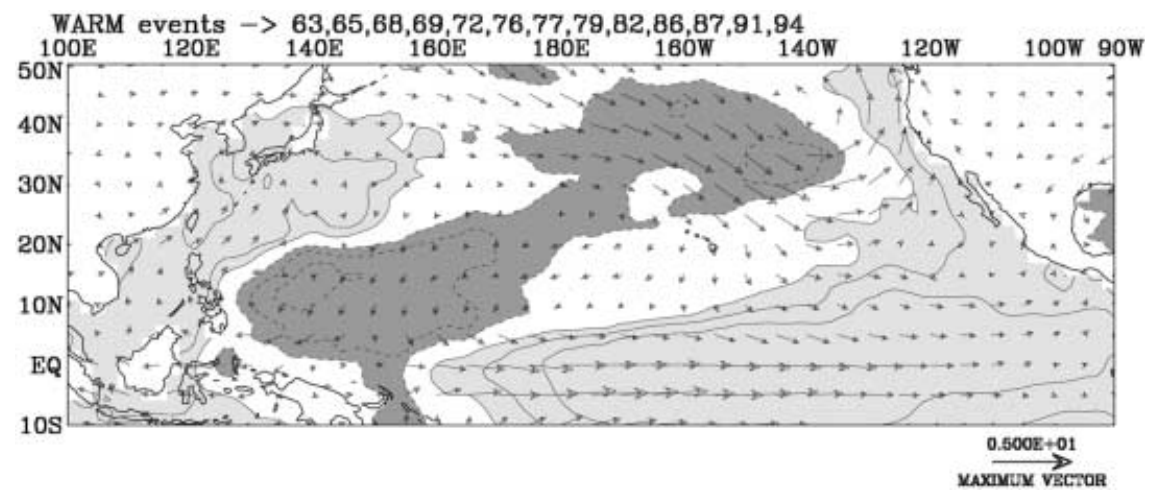

the eastern Pacific, unlike the stronger circulation anomaly in the western North Pacific during warm winters, e.g. in Fig. 4a. Although a weak anticyclonic anomaly is found in the Philippine Sea and the South China Sea, the circulation in East Asia is near normal. In other words, there is no obvious evidence supporting the weakened northeasterly circulation except in the South China Sea. Similar conditions are also found in the composites for the 9 La Niña marked in Table 1.

Results of numerical simulations presented in Sect. 5 also support this argument. The contribution of the SST anomaly in the central/eastern equatorial Pacific to the atmospheric responses is found mainly in the central and northern Pacific. The consistent results of both empirical and numerical studies suggest that ENSO alone is not enough to explain the effect of ocean-atmosphere interaction on the winter SAT in Taiwan and marine East Asia. Instead, the processes that can induce vigorous ocean-atmosphere interaction in the western North Pacific are the essence of the problem.

On the other hand, the interannual SST fluctuations in the western North Pacific are often preceded by SST anomalies in the central/eastern equatorial Pacific, although some of them are very weak. Our calculation indicates that the lag correlation between the WNPSST index in January and the Niño 3.4 index in November of the previous year is greater than 0.8 . While the correlation is high, the amplitude of the SST dipole in the western North Pacific is apparently not in proportion to the strength of the ENSO. It follows that the ENSO signals in the central/eastern equatorial Pacific do not always precondition the ocean-atmosphere state in the western North Pacific, as suggested by Wang et al. (2000), to trigger a vigorous ocean-atmosphere interaction.

The factors determining the efficiency of an ENSO signal to trigger the ocean-atmospheric interaction in the western North Pacific remain unclear and should be studied further. On the other hand, the ocean-atmosphere interaction in the western North Pacific may occur even in non-ENSO years. The appearance of the SST anomaly in the Philippine Sea and Micronesia in the boreal autumn seems to be the key point of this problem. Therefore, it would be important for future studies to pinpoint the mechanism responsible for triggering of this SST anomaly.
Acknowledgement The authors would like to acknowledge the generosity and openness of National Centers for Environmental Prediction to provide the convenient access of reanalysis data for the research community. This study is supported by the National Science Council, ROC, under Grant NSC 89-2119-M-002-003 and NSC 89-2111-M-002-012-AGT.

\section{References}

Halpert MS, Ropelewski CF (1992) Surface temperature patterns associated with the Southern Oscillation. J Clim 5: 577-593

Horel JD, Wallace JM (1981) Planetary-scale atmospheric phenomena associated with the Southern Oscillation. Mon Weather Rev 109: 813-829

Hoskins BJ, Karoly DJ (1981) The steady linear response on a spherical atmosphere to thermal and orographic forcing. J Atmos Sci 38: 1179-1196

Hsu HH (1994) Relationship between tropical heating and global circulation: Interannual variability. J Geophys Res 99: $10473-$ 10489

Ju J, Slingo J (1995) The Asian summer monsoon and ENSO Q J R Meteorol Soc 121: 1133-1168

Kau WS (1998) The NTUGCM's AMIP simulation on the East Asian summer monsoon. Terrestrial Atmos Ocean Sci 9: 197-238

Kiladas GN, Diaz H (1989) Global climate anomalies associated with extremes in the Southern Oscillation. J Clim 2: 1069-1090

Kitoh A (1988) Correlation between the surface air temperature over Japan and the global sea surface temperature. J Meteorol Soc Japan 66: 867-985

Lau KM, Sheu PJ (1988) Annual cycle, quasi-biennial oscillation, and Southern Oscillation in global precipitation. J Geophys Res 93: $10975-10988$

Levitus S (1982) Climatological Atlas of the World Ocean. NOAA Prof Pap 13, US Government Printing Office, Washington, D.C., USA

Li C, Yanai M (1996) The onset and interannual variability of the Asian summer monsoon in relation to land-sea thermal contrast. J Clim 9: 358-375

Lindzen RS, Nigam S (1987) On the role of sea surface temperature variations in forcing low-level winds and convergence in the tropics. J Atmos Sci 44: 2418-2436

Pan YH, Oort AH (1983) Global climate variations connected with sea surface temperature anomalies in the eastern equatorial Pacific Ocean for the 1958-73 period. Mon Weather Rev 111: 1244-1258

Rasmusson EM, Carpenter TH (1982) Variations in tropical sea surface temperature and surface wind fields associated with the Southern Oscillation/El Niño. Mon Weather Rev 110: 354-384

Ropelewski CF, Halpert MS (1987) Global and regional scale precipitation patterns associated with the El Niño/Southern Oscillation. Mon Weather Rev 115: 1606-1626

Ropelewski CF, Halpert MS (1989) Precipitation patterns associated with the high index phase of the Southern Oscillation. J Clim 2: 268-284 
Ropelewski CF, Halpert MS (1996) Quantifying Southern Oscillation-precipitation relationships. J Clim 9: 1043-1059

Trenberth KE (1997) The definition of El Nino. Bull Am Meteorol 78: $2771-2777$

Wang B, Wu R, Fu X (2000) Pacific-East Asian teleconnection: how does ENSO affect East Asian climate? J Clim (in press)
Zhang R, Sumi A, Kimoto M (1996) Impact of El Niño on the East Asian monsoon: a diagnostic study of the $86 / 87$ and '91/92 events. J Meteorol Soc Japan 74: 49-62

Zhang Y, Sperber KR, Boyle JS (1997) Climatology and interannual variation of the East Asian winter monsoon: results from the 1979-95 NCEP/NCAR reanalysis. Mon Weather Rev 125: 2605-2619 